\title{
Opposite effects of cGMP-dependent protein kinase on cGMP production by soluble and particular guanylyl cyclase in adult ventricular myocytes
}

\section{Liliana Castro* and Rodolphe Fischmeister}

Address: INSERM-U769, Faculty of Pharmacy, Chatenay Malabry, France

Email: Rodolphe Fischmeister - fisch@vjf.inserm.fr

* Corresponding author

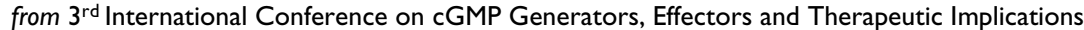 \\ Dresden, Germany. 15-17 June 2007 \\ Published: 25 July 2007 \\ BMC Pharmacology 2007, 7(SuppI I):PI0 doi:I0.II86/I47|-22I0-7-SI-PI0
}

This abstract is available from: http://www.biomedcentral.com/I47I-22 I0/7/SI/PI0

(C) 2007 Castro and Fischmeister; licensee BioMed Central Ltd.

\section{Background}

Both particulate (pGC) and soluble guanylyl cyclases (sGC) synthesize cGMP. While sGC is activated by nitric oxide (NO), pGC is activated by natriuretic peptides (NPs) such as ANP or BNP. Physiological effects of cGMP are mainly mediated by cGMP-dependent protein kinase (PKG) and cGMP phosphodiesterases (PDEs), namely PDE2 and PDE5. We hypothesised that PKG may underlie regulatory feedback in cGMP signals produced by pGC and sGC activation in adult rat ventricular myocytes (ARVMs).

\section{Materials and methods}

To test this hypothesis, subsarcolemmal cGMP signals elicited by NO-donors or NPs in the presence of the PKG inhibitor, KT5823 (KT, $50 \mathrm{nM}$ ) were monitored in ARVMs. Myocytes were infected by an adenovirus expressing the WT rat olfactory cyclic nucleotide-gated channel CNGA2 and the cGMP-gated current $\left(I_{\mathrm{CNG}}\right)$ was recorded by the whole-cell patch-clamp technique.

\section{Results}

Application of the membrane permeant cGMP analog Sp8-pCPT-cGMPS (Sp-8, $100 \mu \mathrm{M})$ induced a large $I_{\mathrm{CNG}}$ current in myocytes infected by CNGA2 adenovirus, but not in control cells. KT increased 3-fold the $I_{\mathrm{CNG}}$ current followed by activation of sGC by $S$-nitroso- $N$-acetyl-penicillamine (SNAP, $100 \mu \mathrm{M}$ ). This effect was abolished in the presence of the non selective PDE inhibitor IBMX
(100 $\mu \mathrm{M}$ ) or a selective PDE5 inhibitor (sildenafil, 100 nM). Surprisingly, KT decreased (by 50\%) the $I_{\mathrm{CNG}}$ current stimulated by ANP (10 nM and $100 \mathrm{nM}$ ) in a PDE-independent manner, but had no effect on total cGMP content measured by radioimmunoassay, which is controlled by PDE2 and PDE5 subtypes.

\section{Conclusion}

Our results suggest that in ARVMs the subsarcolemmal cGMP pools generated by sGC or pGC are differentially regulated by PKG. In the sGC pool, PDE5 mediates the effects of PKG, while in the pGC pool, the PKG effect is independent of PDE activity. These differential regulations of cGMP signals may underlie the specific effects of NPs and NO-donors on cardiac function. 